\title{
Software review: A process change model to meet the Enterprise Marketing Automation (EMA) vision \\ Received: 20th July, 2000
}

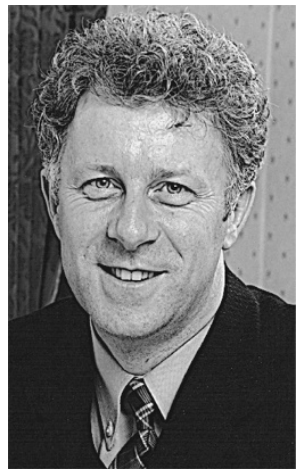

\section{Shaun Doyle}

is Chairman of Intrinsic, a campaign management software company. The focus of the business is the provision of software and database marketing consultancy services aimed at helping clients manage their customer communications more intelligently and effectively. A co-founder of the company with Steve Treadwell, he is responsible for management of the business consultancy team and the strategic direction of the company. He has extensive experience in the design, development, implementation and exploitation of customer-focused database marketing systems in a number of business sectors. These include financial services, retail, leisure, charity and telecommunications. He has been involved in the design and building of over 50 marketing databases in blue chip organisations.

$\mathrm{He}$ is well known in the industry, regularly speaking and running specialist workshops at leading industry conferences. He has had a number of papers published in the UK and overseas on the application of database marketing.

\section{John Georghiou}

is a Business Consultant with Intrinsic, specialising in process change.

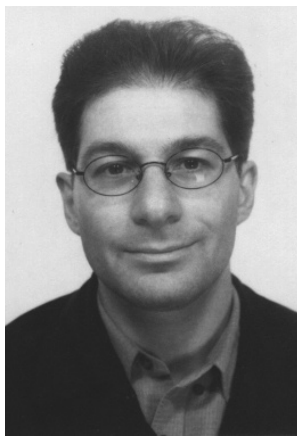

Abstract The last few years have seen an explosion in the technologies to support the Enterprise Marketing Automation Vision (EMA), as an important pillar in meeting corporate customer relationship management (CRM) objectives. Much of the effort spent by organisations is on the selection and deployment of these technologies with little recognition of the central importance of people and process changes to the success of these projects. This paper outlines a framework for looking at the process change issues affecting the realisation of the EMA and CRM benefits.

Shaun Doyle Intrinsic Ltd, Gloucester House, Gloucester Road, Faringdon, Oxon SN7 7HY, UK.

Tel: +4401367 240 003; Fax: +4401367 244 604, e-mail:

Shaun.Doyle@intrinsic. co.uk

\section{EVOLUTION OF ENTERPRISE MARKETING AUTOMATION TECHNOLOGIES}

The last five years has seen the evolution of technologies to support the marketing process. These initially started as campaign management systems. They were extended to allow key elements of the communication execution process to be automated, hence the term marketing automation systems. Over the last year or so these systems have evolved further and are being used to coordinate marketing and non-marketing communications, eg arrears communications across the whole of an enterprise. This technology is generally called Enterprise Marketing Automation (EMA).

These systems are still expanding at such a rate that this term does not really describe the full extent of integration with other elements such as:

- workflow

- behavioural analysis

- decision support

- content management

- channel management. 


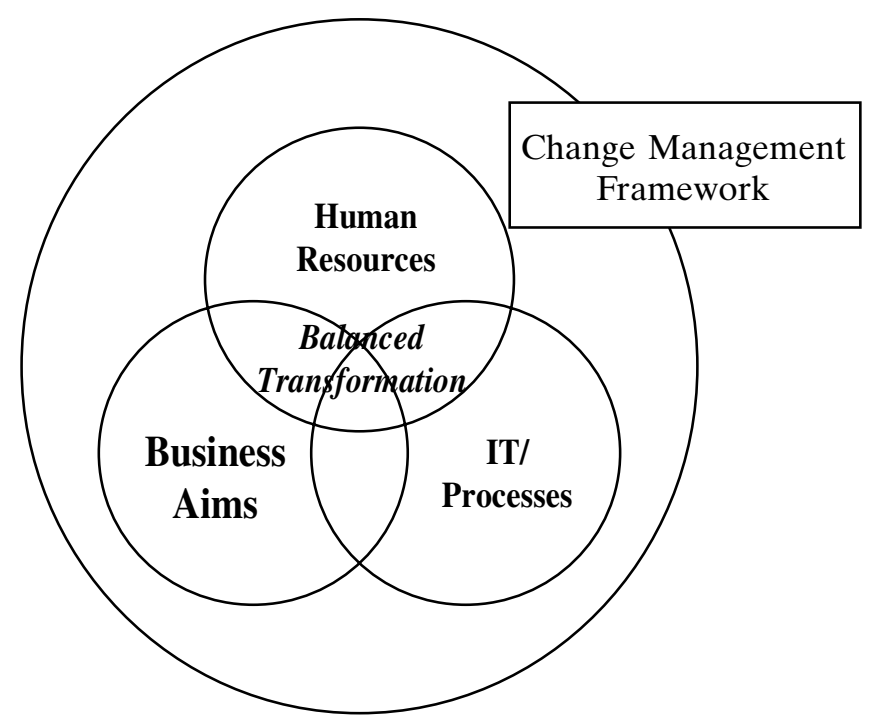

Figure 1

The result is the continuous evolution of the technology to support the marketing communication process. The growth of real-time marketing will continue to fuel this evolution process further.

What has happened over the last few years is that the technology is changing at such a rate that most marketing organisations cannot cope and the technology is not being deployed effectively, with few organisations realising the full potential. The key hurdle is no longer the technology, it is the ability of an organisation to use it. Perhaps the reason for this failure is that little serious effort is going into managing the organisational, people and process change implications.

To enable this transition a framework for the management of change is required to ensure that a balance is achieved between the three pillars of an implementation: human resources, business aims and information technology (IT)/processes (see Figure 1). The key to success is a balanced transformation that takes into account the three elements.

\section{CHANGE MANAGEMENT DELIVERABLES}

A key factor in delivering successful change is the development of both hard and soft change deliverables. These should focus on the work itself rather than on the abstractions such as culture or behaviour. Indeed, the softer aspects of the change process are largely a by-product of the delivery of clear hard products that support the EMA implementation.

Change activity should be directed towards:

- planning marketing business requirements and involvement in the technology procurement process

- understanding the use of technology and the cost of its ownership; exploiting it to meet the business objectives stated

— defining clear roles and responsibilities for the project and its management after delivery

- changing processes to enable teams to concentrate on high-value activities and transferral of learning 


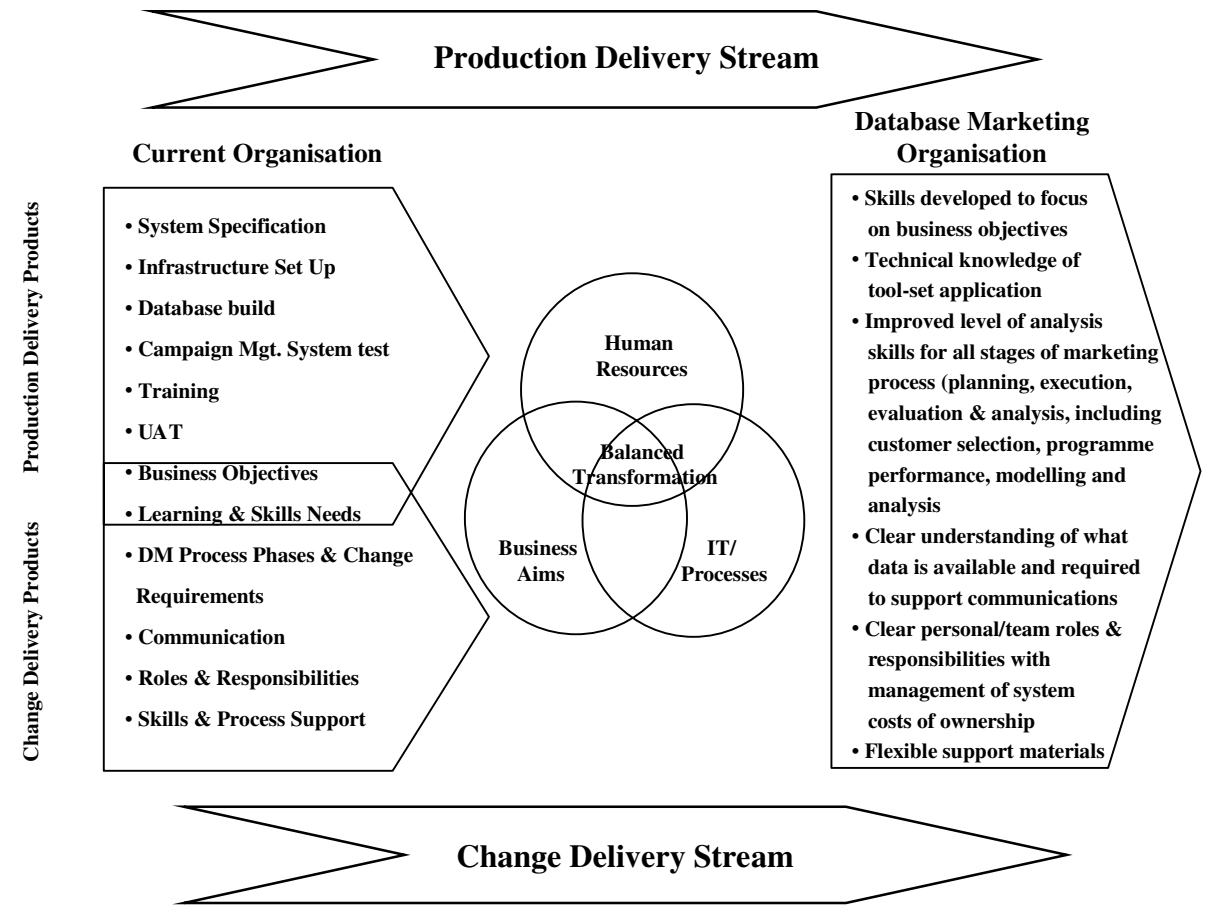

Figure 2

- training, development and user support through clear communication structures across IT and EMA users

- flexible tools that reinforce marketing business objectives.

The main objective should be to shift people from the current organisation structure and processes to a customercentric framework that is proficient in the use of the EMA technology, has a clear understanding of data and can maintain a focus on the new marketing business objectives.

\section{CRITICAL SUCCESS FACTORS FOR CHANGE}

The foundations of success in a change management programme lie in a number of key factors that have to be in place at the project initiation stage:

- pressure for change
- leadership and vision

- capable people

- actionable first steps

- effective rewards.

It is important to recognise that if any one factor is missing any potential statement of the success of the project will be compromised. More importantly, any future business requirements and technology development will be hindered by a retrospective project and cynicism, which will be difficult to overcome.

\section{A FRAMEWORK FOR CHANGE MANAGEMENT}

The framework represented in Figure 2 shows the production and change delivery streams for an EMA project. Each has a range (though not exhaustive) of the products that need to be delivered to move from the current organisation to the new EMA marketing model. The 
attributes of the new organisation are constructed from a combination of activities that derive from a balanced approach to management of human resources, business aims and

IT/marketing processes, throughout the EMA project.

\section{TEAM COMPOSITION}

The change delivery team should comprise people chosen from across the EMA project stakeholder departments.

Team members should typically be users and managers of the marketing department, and representatives from associated functions.

It is also essential that IT is represented at both a management and delivery level. It may also be appropriate in some cases for back office functions to be represented as well as third parties, eg suppliers.

\section{FLAT TEAM STRUCTURE}

Some of the team can perform dual roles on both the production and change delivery teams. It is important that both teams maintain the business objectives of the project so that changing human resource activities and IT and business processes will reflect these outcomes. Team members should be from across the organisational hierarchy and all activities should be strictly managed using a 'flat structure' environment. If necessary the project sponsor should reinforce this point by attending change delivery stream meetings and setting an appropriate example.

\section{STRUCTURED REPORTING PROCESS}

Both production and change management delivery streams should report directly to the departmental sponsor. If the project has a steering committee or project board then direct reports to these bodies will be necessary, however. Deploying this structure will have the following benefits:

- the most fundamental aspect of this type of change structure is that it re-defines processes of communication and reporting from a hierarchical model to a model which is not hampered by traditional lines of communication and reporting. The change delivery team will be critical in the monitoring and evaluation of the project after implementation. This will ensure that the change management stream benefits are realised

- the team as a group should in time achieve consensus on the business objectives, processes and human resource needs. Bridges will be built across departments where previously they may not have existed. These 'associations' will prove invaluable in reaching agreement on how the cost of system ownership will be managed and will drive out the roles and responsibilities to support the project when it has gone live.

\section{DISCOVERY AND ANALYSIS}

This initial stage of the change management process will set the scale and scope of activities within the change management stream. It will need to:

- define changed roles and responsibilities

- propose a system to log and manage issues and risks

- develop a change management project implementation plan.

In Figure 2 business objectives are clearly placed within both the production and 
change delivery streams. Strict assessment, agreement and version control of these outcomes needs to be maintained.

Activities during this phase include an analysis of the current marketing organisation, utilising questionnaires, interviews and focus groups, to assess where it is now. Then, using gap analysis, the team will need to compare this with its desired state. Key areas and deliverables will be:

- review and development of marketing business objectives: a marketing objectives report should be prepared with a quantification of benefits to be provided, the priority attached to each and the level of difficulty to implement them assessed

— the learning and skills needs analysis of those who will be using and managing the EMA system(s) should be constructed to which a set of actions should be mapped in the project plan

- communication: how and what messages will be communicated? How will the project be maintained in people's minds? What progress messages need to be delivered? How will problems be communicated and what mechanism will the project use for receiving information, eg user suggestions? The change management team will need to ensure for staff that there is a legitimate procedure to manage their concerns and to create a supportive environment in which fears can be openly expressed. This will also bring people's resistance to the change to the surface. A resistance management strategy should be identified. Reference should also be made to proposed recognition and reward structures

— roles and responsibilities: who will be accountable and responsible for activities in marketing processes?
What and how are other stakeholders to be consulted and informed of decisions and outputs?

- skills and processes support: for example, across the project different stakeholder groups will have a varied set of requirements for new skills. The marketing manager will require a more in-depth knowledge of the new system and its components than a user will.

Discovery activities and their development towards the change management deliverables of the project will involve the change team in running workshops and facilitating meetings with people from across the organisation. This is an informal launch of the change activity and an opportunity to involve people in the process so that they own the deliverables as they are developed.

\section{CHANGE AWARENESS}

Each of the areas described above will need to be developed towards the outcome that has been decided upon. How will each of these activities be taken forward? For example, commitment to the business objectives by users can be fostered through 'business' workshops where objectives and their implementation can be discussed. Learning and skills needs having been assessed will need to be discussed with the relevant training departments and/or suppliers of the technology. The IT department should be involved in this process by talking to users/others about:

- the architecture of the system

- what data will be incorporated into the system

- software demonstrations

- the setting of expectations at an early stage of what users can expect the system to do when it goes live. 
As plans and activities are decided upon so should the way that project messages and information will be communicated to marketing project stakeholders. There should be a symbolic end to 'the way things are done now', opening the debate and dialogue about the future.

Several communication messages will be required as different people will be at different stages on the change curve, addressing their concerns and providing the answer to the question, 'what does the change mean for me?'.

A visual identity for the project may be developed, with workshops and focus groups run to develop awareness and understanding of it. The deliverables of this phase are a:

- vision of the future state of the marketing operation, quantified to high level structures, processes and the types of roles and responsibilities envisaged

- statement about the technology that is being implemented, how it will help the marketing operation

- communications plan and the delivery of the above messages in a range of launch events

- project identity, name and, perhaps, logo.

\section{EMBEDDING CHANGE}

This is the implementation stage of the change project. Its objectives are to ensure that the individuals and groups who are affected by the change

programme are supported throughout the process, and that their commitment to the changes is sustained once the formal project has finished.

This phase of the project may include activities outside the scope of this framework, such as user training on the new system, business awareness workshops, or new business process implementation. Many of these activities will be covered by the production delivery. The deliverables of this phase are:

- identified 'straw-man roles and responsibilities' workshops with all stakeholders

- new process and procedures being supported by workshop and seminar activities to discuss and understand how the new process will support the agreed marketing business objectives to a detailed level

- training and development activities for the technology and processes, supplier coaching, development and construction of support materials

- data awareness workshops by the IT department.

This phase is about delivering products, the system is of course the key deliverable for the production stream. The change stream will deliver marketing business process guides, mapped roles and responsibilities to new processes, and training and coaching events. (Giving users the opportunity of 'playing' with the system pre go-live with their data).

\section{BENEFITS ADOPTION AND REALISATION}

It is important that the change programme has a formal end, rather than just drifting to a close once the project has gone live. Although people will have been involved, there will be some trepidation and anxiety at using the live system.

The change team should act as coaches at this stage, always close at hand if people have questions or want to talk through something. Additionally, the production delivery stream will have provided for IT and supplier time to 
troubleshoot issues. What is important is that, after implementation, the team faces that people are used to seeing do not disappear.

During this process the initial performance and behaviour of the organisation should be reviewed against the objectives set. The activities during this phase are to achieve sign-off for the project from the sponsor, measure the benefits accrued, and run post-project learning days where and when required. The key deliverables of this phase are the provision of a benefits report and a learning report and action plan.

The change management team should also drive the publicity, presentations and awards to thank people publicly for their efforts and promote the new marketing organisation internally and externally.

\section{CONCLUSION}

In this paper a framework to enable successful change in an EMA project has been introduced and discussed. Successful change revolves around three simple components. People, people and people. Good technology and effective processes help, but, essentially, it is people's understanding of the data, the technology and the use of these that matter.

For every EMA project, individual organisations will need to define what success means to them. The authors believe that it goes beyond technology and training being delivered on time, beyond creating an organisation that enables marketing teams to exploit process and systems change. These are significant, but, ultimately, success is about creating a marketing organisation that thrives on change. 